\title{
Thiosulfate sulfurtransferase and UDP- glucuronosyltransferase activities in cholestatic rat liver induced by common bile duct ligation
}

\author{
Jong-Sool $\mathrm{Ihm}^{1}$ and You-Hee $\mathrm{Kim}^{1,2}$ \\ 1 Department of Biochemistry, Keimyung University \\ School of Medicine, Taegu, 700-712, Korea \\ 2 Corresponding author \\ Accepted 10 September 1997
}

Abbreviations: UDP-GT, UDP-glucuronosyltransferase; $\mathrm{CBD}$, common bile duct

\begin{abstract}
We have investigated the effect of cholestasis on the hepatic thiosulfate sulfurtransferase (rhodanese) and UDP-glucuronosyltransferase (UDP-GT) activities in rats. Rhodanese activities in the liver cytosol, mitochondria and microsomal fractions as well as in the rat serum, and UDP-GT activity in the microsome have been investigated for a period of $\mathbf{4 2}$ days after common bile duct (CBD) ligation. The cytosolic rhodanese activity showed a significant decrease between the first through the 42nd day, and the mitochondrial activity showed a significant decrease between the 7th through the 42nd day after CBD ligation compared to the activities from the sham operated control, respectively. In the case of microsomal preparation, both rhodanese and UDP-GT also showed significant decrease in their activities after the ligation for the former enzyme between the 14th and the $42 \mathrm{nd}$ days, and for the latter enzyme between the third and 42nd days, respectively. On the other hand, the serum rhodanese activity increased markedly soon after the ligation, exhibiting the peak activity after 1 day of CBD ligation with about 4.6-fold increment. The activity subsequently decreased gradually reaching to the control level at the 42nd day post-ligation. Enzyme kinetic parameters of hepatic rhodanese and UDP-GT were analyzed using sodium thiosulfate and $p$ nitrophenol as substrates, respectively, with the preparations from the 28th day post-ligation. The results indicated that although the $K_{m}$ values of these enzymes were about the same as the sham-operated control, the $\mathrm{V}_{\max }$ values of the both enzymes decreased significantly. These results, therefore, suggest that the biosynthesis of rhodanese and UDP-GT have
\end{abstract}

been reduced in response to cholestasis, and that the elevation of rhodanese activity in the serum is most likely due to leakage from the liver subsequent to CBD ligation.

Keywords: thiosulfate sulfurtransferase (rhodanese), UDP-glucuronosyltransferase, cholestatic rat liver

\section{Introduction}

Thiosulfate sulfurtransferase (thiosulfate: cyanide sulfurtransferase, EC 2.8.1.1, rhodanese) is one of the conjugating enzyme which converts cyanides, sulfites, organic sulfinates and dithiols to less toxic sulfur compounds (Westly, 1973, 1980, 1981; Kim, 1979). The enzyme is mainly present in the mammalian liver (Westly, 1973, 1980), and in the blood (Drawbaugh and Marrs, 1987). UDP-glucuronosyltransferase (UDP-glucuronate $\beta$-Dglucuronosyltransferase, acceptor unspecific, EC 2.4.1.17, UDP-GT) is another class of conjugating enzymes which is mainly localized in endoplasmic reticulum of the liver (Kim, 1979; Kasper and Henton, 1980) and known to convert phenols, alcohols, amines and fatty acids to less harmful and more water-soluble metabolites by glucuronate conjugation, although its acceptor molecule is not clearly defined (Kim, 1979; Kasper and Henton, 1980).

The common bile duct (CBD) ligated rats have been widely used as an experimental model in human extrahepatic cholestasis (Kaplan and Righetti, 1970, Righetti and Kaplan, 1972; Kryszewski et al., 1973). In human, anatomical or mechanical obstruction of CBD occurs most commonly due to gallstones, neoplasms, or strictures, and less commonly due to primary biliary cirrhosis, cholangitis, hepatitis (Mezey, 1976; Rosalki, 1976). In chronic cholestatic liver in humans and rats, the hepatocytes are particularly susceptable, thus yielding functional and morphological derrangements to develop into pathological conditions, such as necrosis, inflammation, fatty changes, biliary hyperplasia, fibrosis and cirrhosis (Desmet, 1979; Kountouras et al., 1984; Chang et al., 1987; Kim et al., 1989).

To understand biochemical alteration(s) under the cholestasis, many laboratories have studied several hepatic enzymes in experimental animals (Kwak, 1985; Kwak et al., 1988; Mun and Kwak, 1989; Kwon et al., 1990; Kwak and Lee, 1992; Mun 1994; Park et al., 1994; Ra et al., 1994; Ihm et al., 1995). However, the possible changes of the rhodanese and the UDP-GT activities under the cholestasis induced by CBD ligation have not yet been investigated. Previously, however, we have reported 
that cholestasis induced by CBD ligation affects isozyme pattern of hepatic aryl sulfotrasferase in rats, and aryl sulfotransferase was shown to mediate detoxication (Ihm et al., 1995). In the present study, we have systematically investigated the liver rhodanese and UDP-GT activities with the subcellular fractions prepared from the cholestatic rat liver induced by CBD ligation for a period of 42 days. In addition, $K_{\mathrm{m}}$ and $V_{\max }$ values for these enzymes were also analyzed with the 28th day post-CBD ligated rat liver preparations and compared to those values obtained from the sham-operated.

\section{Materials and Methods}

\section{Chemicals}

Potassium cyanide, sodium thiosulfate pentahydrate, ferric nitrate nonahydrate, ferric thiocyanate, UDP-glucuronic acid sodium, $p$-nitrophenol, $p$-nitrophenyl- $\beta$-D-glucuronide, bovine serum albumin, Triton X-100, glycine, rhodanese (thiosulfate sulfurtransferase, type II, from bovine liver), UDP-GT (type III, from bovine liver) and bovine albumin standard (10 ml/100 mg) were purchased from Sigma Chemical Co. (St. Louis, USA).

\section{Animals}

Normal male rats of the Sprague-Dawley strain, weighing between 320 and $350 \mathrm{~g}$, were used for the experiments. All animals were maintained on a pellet diet obtained commercially (Sam Yang Food Co., Wonju, Korea) and tap water. During surgery, rats were anesthetized lightly with ether, and the abdomen was opened through a median line incision. The CBD was pulled out and then doubly ligated close to the liver and excised just below the confluence of the lobular ducts. Control animals were subjected to sham operation (midline laparectomy). Each experiment was carried out with a group of 5 rats. Rats were sacrificed after $0.5,1,2,3,7,14,28$ and 42 days following the operation. The livers were excised following perfusion (see below), and blood was collected from the aorta. The serum was separated by centrifugation and was stored at $-20^{\circ} \mathrm{C}$ until use. All animals had been fasted for $12 \mathrm{~h}$ prior to sacrifice or surgery.

\section{Subcellular fractionation}

The livers were perfused via the portal vein with cold 0.25 $M$ sucrose, and then excised, blotted, weighed, minced and homogenized in 9 vol. of $0.25 \mathrm{M}$ sucrose. Each homogenate was subjected to cell fractionation. Cytosol, mitochondria and microsomes were isolated by the sucrose linear density gradient centrifugation method (Kwak and $\mathrm{Kwak}, 1986)$, and stored at $-80^{\circ} \mathrm{C}$. All the isolation procedures were performed at 2 to $4^{\circ} \mathrm{C}$. The cytosolic, mitochondrial, and microsomal fractions (hepatic subcellular fractions) were used for enzyme assay.

\section{Enzyme assays}

The hepatic subcellular preparations and serum rhodanese activities were measured in a spectrophotometer (Varian, Cary 210) according to the method of Westly (1981) using potassium cyanide and sodium thiosulfate as substrate. Ten $\mu$ l of each subcellular preparation and/ or $50 \mu \mathrm{l}$ of serum were incubated with $0.2 \mathrm{ml}$ of $0.24 \mathrm{M}$ potassium cyanide, $0.2 \mathrm{ml}$ of $0.2 \mathrm{M}$ potassium phosphate monobasic, and $0.2 \mathrm{ml}$ of $0.25 \mathrm{M}$ sodium thiosulfate pentahydrate for $20 \mathrm{~min}$. The incubations were terminated by the addition of $0.5 \mathrm{ml}$ of $15 \%(\mathrm{v} / \mathrm{v})$ formaldehyde. The amount of ferric thiocyanate formed by the addition of $1.5 \mathrm{ml}$ ferric nitrate reagent ( $10 \mathrm{~g}$ of ferric nitrate nonahydrate and $20 \mathrm{ml}$ of $65 \%$ nitric acid per $150 \mathrm{ml}$ ) was read by absorbance change at $460 \mathrm{~nm}$. The enzyme activity was expressed as amount of ferric thiocyanate formed per min per $\mathrm{mg}$ of protein for liver preparations or that formed per min per $\mathrm{ml}$ of serum.

The hepatic microsomal UDP-GT activity was measured according to the method of Reinke et al. (1986) with $p$ nitrophenol and UDP-glucuronic acid as substrate. Incubations were performed in $15 \mathrm{ml}$ test tube with $2 \mathrm{ml}$ of $50 \mathrm{mM}$ phosphate buffer, $\mathrm{pH} 7.0$, containing $3 \mathrm{mM}$ UDP-glucuronic acid sodium salt, $1 \mathrm{mM} p$-nitrophenol, 1 $\mathrm{mM}$ magnesium chloride, $0.02 \%$ bovine serum albumin, $0.05 \%(\mathrm{v} / \mathrm{v})$ Triton X-100 solution and $0.2 \mathrm{ml}$ of hepatic microsome. The incubations were initiated by the addition of UDP-glucuronic acid and were terminated after $20 \mathrm{~min}$ by the addition of $0.5 \mathrm{ml}$ of $0.6 \mathrm{M}$ perchloric acid. The precipitated proteins were removed by centrifugation. $p$ Nitrophenol remaining was determined by diluting 0.5 $\mathrm{ml}$ of the supernatant fraction with $2 \mathrm{ml}$ of $1.6 \mathrm{M}$ glycine buffer, $\mathrm{pH} 10.3$, and reading absorbance at $436 \mathrm{~nm}\left(\varepsilon_{436}\right.$ $=7.11 \mathrm{mM}^{-1} \mathrm{Cm}^{-1}$ ). The enzyme activity was expressed as amount of $p$-nitrophenyl- $\beta$-D-glucuronide formed per min per mg of hepatic microsomal protein.

Michaelis-Menten constants $\left(K_{\mathrm{m}}\right.$ and $\left.V_{\max }\right)$ of the enzymes were determined with subcellular fractions of sham operated rat livers and/or cholestatic rat livers at the 28th day after operation, at variable concentrations of sodium thiosulfate (for rhodanese) and $p$-nitrophenol (for UDP-GT). The enzyme kinetic constants were calculated using Lineweaver-Burk plot.

\section{Determination of protein}

The protein concentrations of each subcellular fraction were determined by the biuret reaction (Gornall et al., 1949), using bovine albumin as the reference protein.

\section{Statistical analysis}

Values were expressed as mean \pm SD Statistical evaluation of the experimantal data was evaluated by Student's t-test. $P$ values of $\leq 0.05$ were considered to be significant. 


\section{Results and Discussion}

The effects of the cholestasis on activities of several xenobiotic biotransforming enzymes, such as xanthine oxidase (Kwak, 1985), alcohol dehydrogenase, catalase, microsomal ethanol oxidizing system (Kwak et al., 1988), monoamine oxidase (Mun and Kwak, 1989), glutathione S-transferase, glutathione peroxidase (Kwon et al., 1990), arylesterase, carboxylesterase, cholinesterase (Kwak and Lee, 1992) and aryl sulfotransferase (Ihm et al., 1995) have been previously studied in cholestatic rat liver. Especially, the rhodanese and the UDP-GT are xenobiotic biotransforming enzymes (Kasper and Henton, 1980; Westly, 1980). Nevertheless the changes of the rhodanese and UDP-GT have not been studied under the cholestasis induced by CBD ligation. In order to understand the effects of cholestasis on these enzyme activities, we have determined the activities of cytosolic, mitochondrial and microsomal rhodanese and microsomal UDP-GT in cholestatic rat liver induced by CBD ligation for a period of 42 days. The activity of rhodanese in serum was also measured. Values of $K_{m}$ and $V_{\max }$ for these hepatic rhodanese and UDP-GT at the 28th day after CBD ligation were determined using sodium thiosulfate and $p$ nitrophenol as substrate, respectively.

The cytosolic rhodanese activity in the rat liver showed a significant decrease from the first day to the 42nd day subsequent to CBD ligation (Table 1). The activity of mitochondrial rhodanese also decreased in the cholestatic rat liver, beginning from seventh day after the ligation, and continued to decrease until 42nd day compared to the sham operated liver activity (Table 1). In the case of microsomal rhodanese, the rate of decrease of the activity is least responsive, showing a decrease of the activity at 14th day (Table 1). However, quite contrary to it, the serum rhodanese activity increased markedly soon after the ligation; about 4.6-fold increase was observed at 1 day after the ligation, and then, the activity gradually decreased to the control level at 42nd day of post-ligation (Table 2). In the case of microsomal UDP-GT, the reduced activity was seen on the third day which further decreased on the 42nd day (Table 3).

In order to investigate whether the changes of the rhodanese and UDP-GT activities in the cholestatic rat liver are possibly due to alteration in their catalytic property of the enzyme, $K_{\mathrm{m}}$ and $V_{\max }$ values were determined with 28th day post-CBD ligation preprations. As shown in Table $4, K_{m}$ values of rhodanese did not change significantly compared to those from sham-operated liver in all three preparations of cytosol, mitochondria and microsome. However, $V_{\max }$ significantly decreased in all preparations; $3.3 \mu \mathrm{mol}$ ferric thiocyanate $\mathrm{min}^{-1} \mathrm{mg}$ protein ${ }^{-1}$ vs. 1.35 for cytosol; $4.64 \mu \mathrm{mol}$ ferric thiocyanate $\mathrm{min}^{-1} \mathrm{mg}_{\text {protein }}{ }^{-1}$

Table 2. Activities of serum thiosulfate sulfurtransferase (rhodanese) after ligation of $\mathrm{CBD}$ in rats. The data are expressed as mean $\pm S D$ with 5 rats in each group. Sham: sham operation.

\begin{tabular}{clc}
\hline $\begin{array}{c}\text { Day(s) } \\
\text { following } \\
\text { ligation }\end{array}$ & \multicolumn{2}{c}{$\begin{array}{c}\text { Rhodanese activities } \\
\left.\text { (nmol ferric thiocyanate } \mathrm{min}^{-1} \mathrm{ml}^{-1}\right)\end{array}$} \\
\cline { 2 - 3 } 0.5 & Sham & CBD ligation \\
\hline 1 & $204 \pm 55$ & $887 \pm 225^{\mathrm{c}}$ \\
2 & $210 \pm 50$ & $1,167 \pm 378^{\mathrm{c}}$ \\
3 & $207 \pm 52$ & $958 \pm 264^{\mathrm{c}}$ \\
7 & $205 \pm 52$ & $926 \pm 200^{\mathrm{C}}$ \\
14 & $207 \pm 53$ & $637 \pm 120^{\mathrm{c}}$ \\
28 & $209 \pm 50$ & $543 \pm 125^{\mathrm{c}}$ \\
42 & $202 \pm 48$ & $313 \pm 81^{\mathrm{a}}$ \\
\hline
\end{tabular}

${ }^{a} P<0.05 ;{ }^{c} P<0.01 ;{ }^{a}, \mathrm{c}$ values were compared with that of sham operated control.

Table 1. Activities of cytosolic, mitochondrial and microsomal thiosulfate sulfurtransferase (rhodanese) in cholestatic rat liver after CBD ligation. The data are expressed as mean \pm SD with 5 rats in each group; Sham: sham operation.

\begin{tabular}{|c|c|c|c|c|c|c|}
\hline \multirow{3}{*}{$\begin{array}{l}\text { Day(s) } \\
\text { following } \\
\text { ligation }\end{array}$} & \multicolumn{6}{|c|}{ Rhodanese activities ( $\mu \mathrm{mol}$ ferric thiocyanate $\mathrm{min}^{-1} \mathrm{mg} \mathrm{protein}^{-1}$ ) } \\
\hline & \multicolumn{2}{|c|}{ Cytosol } & \multicolumn{2}{|c|}{ Mitochondria } & \multicolumn{2}{|c|}{ Microsome } \\
\hline & Sham & CBD ligation & Sham & CBD ligation & Sham & CBD ligation \\
\hline 0.5 & $3.06 \pm 0.34$ & $2.85 \pm 0.33$ & $4.35 \pm 0.91$ & $4.18 \pm 0.81$ & $0.24 \pm 0.07$ & $0.26 \pm 0.07$ \\
\hline 1 & $3.10 \pm 0.33$ & $2.61 \pm 0.29^{a}$ & $4.31 \pm 0.91$ & $4.02 \pm 0.76$ & $0.25 \pm 0.07$ & $0.35 \pm 0.10$ \\
\hline 2 & $3.10 \pm 0.32$ & $2.50 \pm 0.32^{\mathrm{a}}$ & $4.30 \pm 0.92$ & $3.76 \pm 0.81$ & $0.25 \pm 0.07$ & $0.31 \pm 0.09$ \\
\hline 3 & $3.08 \pm 0.31$ & $2.27 \pm 0.30^{b}$ & $4.30 \pm 0.92$ & $3.25 \pm 0.94$ & $0.25 \pm 0.07$ & $0.31 \pm 0.07$ \\
\hline 7 & $3.09 \pm 0.30$ & $1.83 \pm 0.32^{c}$ & $4.25 \pm 0.90$ & $2.44 \pm 0.76^{b}$ & $0.25 \pm 0.06$ & $0.25 \pm 0.06$ \\
\hline 14 & $3.07 \pm 0.29$ & $1.11 \pm 0.29^{c}$ & $4.26 \pm 0.86$ & $2.18 \pm 0.73^{b}$ & $0.24 \pm 0.06$ & $0.12 \pm 0.05^{b}$ \\
\hline 28 & $3.09 \pm 0.29$ & $1.06 \pm 0.27^{c}$ & $4.26 \pm 0.86$ & $1.14 \pm 0.56^{c}$ & $0.24 \pm 0.06$ & $0.10 \pm 0.04^{b}$ \\
\hline 42 & $3.07 \pm 0.28$ & $1.03 \pm 0.31^{c}$ & $4.25 \pm 0.85$ & $1.08 \pm 0.53^{c}$ & $0.24 \pm 0.06$ & $0.09 \pm 0.04^{b}$ \\
\hline
\end{tabular}

${ }^{\mathrm{a}} P<0.05 ;{ }^{\mathrm{b}} P<0.01 ;{ }^{\mathrm{c}} P<0.01 ;{ }^{\mathrm{a}, \mathrm{b}, \mathrm{c}}$ values were compared with that of sham operated control. 
vs. 1.68 for mitochondria; and $0.289 \mu \mathrm{mol}$ ferric thiocyanate $\min ^{-1} \mathrm{mg}$ protein ${ }^{-1}$ vs. 0.159 for microsomal fractions, respectively. Similarly, the $V_{\max }$ value of microsomal UDP-GT also decreased compared to the control (29.2 nmol $p$-nitrophenyl $\beta$-D-glucurouide $\mathrm{min}^{-1} \mathrm{mg}_{\text {protein }}{ }^{-1}$ vs. 11.5), although the $K_{m}$ value did not change significantly (Table 5).

The fact that the decreased rhodanese activity in the liver cytosol after the CBD ligation accompanied by the

Table 3. Activities of liver microsomal UDP-GT after ligation of CBD in rats. The data are expressed as mean \pm SD with 5 rats in each group. Liver of sham, sham operated rat liver.

\begin{tabular}{ccc}
\hline $\begin{array}{c}\text { Day(s) } \\
\text { following } \\
\text { ligation }\end{array}$ & $\begin{array}{c}\text { UDP-GT activity } \\
\left.\text { (nmol } p \text {-nitrophenyl } \beta \text {-D-glucuronide } \text { min }^{-1} \text { mg protein }^{-1}\right)\end{array}$ \\
\cline { 2 - 3 } & Liver of sham & Cholestatic liver \\
\hline 0.5 & $21.9 \pm 2.8$ & $19.5 \pm 3.5$ \\
1 & $21.0 \pm 2.9$ & $18.6 \pm 4.3$ \\
2 & $22.4 \pm 3.1$ & $18.4 \pm 5.4$ \\
3 & $21.8 \pm 2.7$ & $11.2 \pm 5.1^{\mathrm{b}}$ \\
7 & $22.1 \pm 3.0$ & $10.3 \pm 4.7^{\mathrm{b}}$ \\
14 & $22.6 \pm 2.8$ & $9.9 \pm 3.4^{\mathrm{c}}$ \\
28 & $22.3 \pm 2.5$ & $8.9 \pm 3.2^{\mathrm{c}}$ \\
42 & $22.5 \pm 2.6$ & $5.7 \pm 2.7^{\mathrm{C}}$ \\
\hline
\end{tabular}

${ }^{b} P<0.01 ;{ }^{c} P<0.001 ;{ }^{b, c}$ values were compared with that of sham operated control. increased activity in the serum poses an interesting proposition in that the liver rhodanese might have been leaked easily into the blood stream due to an increased permeability of the hepatocyte membrane, caused by cholestasis as pointed out previously (Park et al., 1994; Inm et al. 1995). It should be also noted that the lower $V_{\text {max }}$ values of rhodanese in all subcellular fractions of CBD-ligated liver as well as that of the microsomal UDPGT might reflect the lower levels of the activities in CBDligated liver. In addition, it is also concievable that the reduced enzyme levels of both rhodanese and UDP-GT accompanied by lower $V_{\max }$ values in CBD-ligated liver preparations might have been to reduced biosynthetic capability of the cholestatic liver where functional abnormalities of the liver are expected to develop.

\section{References}

Chang, D. S., Kwak, J. S. and Shon, T. J. (1987) An ultrastructural study on the proliferative changes of bile ductules after ligation of common bile duct. Kyungpook Univ. Med. J. 28: 113-122

Desment, V. J. (1979) Cholestasis: extrahepatic obstruction and secondary biliary cirrhosis. In Pathology of the Liver (MacSween. R. M. N., Anthony, P. P. and Scheudur, P., eds.), pp. 272-305, Churchil Livingstone, New York

Drawbaugh, R. B. and Marrs, T. J. (1987) Interspecies differences in rho-danese (thiosulfate sulfurtransferase, EC 2.8.1.1) activity in liver, kidney and plasma. Comp. Biochem. Physiol. [B] 86: 307-310

Gornall, A. G., Bardawill, C. J. and David, M. M. (1949) Determination of serum protein by means of biuret reaction. J. Biol. Chem. 177: 751-766

Table 4. Kinetic parameters of thiosulfate sulfurtransferase (rhodanese) from cholestatic rat liver. Thiosulfate sulfurtransferase activities were determined using sodium thiosulfate and potassium cyanide at $25^{\circ} \mathrm{C}$ for cytosolic, mitochondrial and mictosomal fractions of sham-operated male rat livers and cholestatic male rat livers at the 28th day after CBD ligation. The data are expressed as mean \pm SD with 5 rats in each group. Liver of sham, sham operated rat liver.

\begin{tabular}{lcccc}
\hline \multirow{2}{*}{$\begin{array}{c}\text { Cell } \\
\text { fraction }\end{array}$} & \multicolumn{2}{c}{$\begin{array}{c}K_{\mathrm{m}} \\
(\mathrm{mM})\end{array}$} & \multicolumn{2}{c}{$\begin{array}{c}V_{\max } \\
\left(\mu \mathrm{mol} \text { ferric thiocyanate } \mathrm{min}^{-1} \mathrm{mg} \mathrm{protein}^{-1}\right)\end{array}$} \\
\cline { 2 - 6 } & Liver of sham & Cholestatic liver & Liver of sham & Cholestatic liver \\
\hline Cytosol & $247 \pm 42$ & $236 \pm 51$ & $3.63 \pm 0.35$ & $1.35 \pm 0.24^{\mathrm{C}}$ \\
Mitochondria & $265 \pm 47$ & $252 \pm 55$ & $4.64 \pm 0.96$ & $1.68 \pm 0.52^{\mathrm{C}}$ \\
Microsome & $603 \pm 126$ & $581 \pm 138$ & $0.289 \pm 0.066$ & $0.159 \pm 0.046^{\mathrm{b}}$ \\
\hline
\end{tabular}

${ }^{b} P<0.01 ;{ }^{c} P<0.001{ }^{b, c}$ values were compared with that of sham operated rat livers.

Table 5. Kinetic parameters of microsomal UDP-GT from cholestatic rat liver. Experimental conditions were as described in "Materials and Methods". Microsomal fraction of sham operated male rat livers and cholestatic male rat livers at the 28th day after CBD ligation were used for the enzyme assay.

\begin{tabular}{cccc}
\hline \multicolumn{2}{c}{$\begin{array}{c}K_{\mathrm{m}} \\
(\mathrm{mM})\end{array}$} & \multicolumn{2}{c}{$V_{\max }$} \\
\hline Liver of sham & Cholestatic liver & Liver of sham & Cholestatic liver \\
\hline $9.59 \pm 1.61$ & $9.23 \pm 2.14$ & $29.2 \pm 2.6$ & $11.5 \pm 2.8^{\mathrm{C}}$ \\
\hline
\end{tabular}

${ }^{\mathrm{c}} P<0.001$ vs. sham operated control. 
Ihm, J. S., Kim, Y. H. and Kwak, C. S. (1995) Aryl sulfotransferase activity in cholastatic rat liver induced by common bile duct ligation. Korean J. Biochem. 27: 141-147

Kaplan M. M. and Righetti, A. (1970) Induction of rat liver alkaline phos-phatase: the mechanism of the serum elevation in bile duct obstruction. J. Clin. Invest. 49: 508-516

Kasper, C. B. and Henton, A. (1980) Glucuronidation. In Enzymatic Basis of Detoxication (Jacoby, W. B., ed.), Vol. II, pp. 3-36, Academic Press, New York

Kim, B. K. (1979) Enzyme Nomenclature, IUB, pp. 164-165, 228-229, Academic Press, New York

Kim, H. S., Park, J. Y., Kawk, K. S., Choi, Y. H and Chung, J. M. (1989) Morphologic changes of hepatocytes induced by common bile duct ligation. Korean J. Int. Med. 36 : 459-470

Kountouras, J., Billing , B. H. and Scheuer, P. J. (1984) Prolonged bile duct obstruction: a new experimental model for cirrhosis in the rat. Br. J. Exp. Pathol. 65: 305-311

Kryszewski, A. J., Neale, G., Whilfield, J. B. and Moss D. W. (1973) Enzyme changes in experimental biliary obstruction. Clin. Chim. Acta 47: 175-182

Kwak, C. S. (1985) Xanthine oxidase activity in the cholestatic rat liver. Keimyung Univ. Med. J. 4: $125-130$

Kwak, C. S., Kim, Y. H. and Mun, K. C. (1988) Activities of alcohol meta-bolizing enzymes in the cholestatic rat liver. Keimyung Univ. Med. J. 7: 64-75

Kwak, C. S. and Kwak, J. S. (1986) Cell fractionation method of the rat liver. Keimyung Univ. Med. J. 5: 45-53

Kwak, C. S. and Lee, S. H. (1992) Carboxylesterase, arylesterase and cholinesterase activities in cholestatic rat liver induced by common bile duct ligation. Korean Biochem. J. 25: $251-261$

Kwon, Y. C., Mun, K. C. and Kwak, C. S. (1990) Glutathione S-transferase, glutathione peroxidase activities in cholestatic rat liver. Keimyung Univ. Med. J. 9: 159-170

Mezey, E. (1976) Diagnosis of liver disease by laboratory methods and specific liver disease. In The Laboratory in Clinical Medicine (Halsted, J. A., ed.), pp. 417-445, B. W. Saunders, Philadelphia

Mun, K. C. (1994) Correlation between superoxide radical production and hepatic damage induced by bile duct ligation. Korean Biochem. J.27: 346-349

Mun, K. C. and Kwak, C. S. (1989) Monoamine oxidase activity in chole-static rat liver. Keimyung Univ. Med. J. 8: 69-77

Park, E. M., Mun, K. C. and Kwak, C. S. (1994) $\alpha$-D-Mannosidase and $\beta$-Dmannosidase activities in cholestatic rat liver induced by bile duct ligation. Korean $\mathrm{J}$. Biochem. 26: 197-202

Ra, C. Y., Mun, K. C. and Kwak, C. S. (1994) Effects of bile duct ligationon on serum and hepatic 5 '-nucleosidase activities in ethanol intoxicated rats. Korean J. Biochem. 27: 117123

Reinke, L. A, Moyer, M. J. and Notley, K. A. (1986) Diminished rates of glucuronidation and sulfation in perfused rat liver after chronic ethanol administration. Biochem. Pharmacol. 35: 439-441

Righetti, A. B. B. and Kaplan, M. M. (1972) Disparate response of serum and hepatic alkaline phosphatase and 5 '-nucleosidase to bile duct obstruction in the rat. Gastroenterology 62: 1034-1039

Rosalki, S. B. (1976) Enzyme tests in disease of the liver and hepatobili-ary tract. In The Principlniples and Practice of Diagnositic Enzymology (Wilkinson, J. H., ed.), pp. 303360. Edward Arnold, London

Westly, J. (1973) Rhodanese. Adv. Enzymol. Areas Mol. Biol. 39: 327-368

Westly, J. (1980) Rhodanese and sulfate pool. In Enzymatic Basis of Detoxication (Jacoby, W. B., ed.), Vol. II, pp. 245-262, Academic Press, New York

Westly, J. (1981) Thiosulfate: cyanide sulfurtransferase(Rhodanese). In Methods in Enzymology (Jacody, W. B., ed.), Vol. II, pp. 245-262, Academic Press, New York 